\title{
Efficacy and safety of spleen aminopeptide oral lyophilized powder in ameliorating liver injury in infants and children with human cytomegalovirus infection: a single-center study in China
}

\author{
Yanling Wu, Xueting Dong, Runqiu Wu, Xinguo Zheng, Yu Jin, Hui Yang^^ \\ Department of Pediatric Gastroenterology, Children's Hospital of Nanjing Medical University, Nanjing, China \\ Contributions: (I) Conception and design: H Yang; (II) Administrative support: Y Jin; (III) Provision of study materials or patients: Y Wu, X Dong, R \\ Wu, X Zheng; (IV) Data analysis and interpretation: Y Jin, H Yang; (V) Manuscript writing: H Yang; (VI) Final approval of manuscript: All authors; \\ (VII) Final approval of manuscript: All authors. \\ Correspondence to: Hui Yang. Department of Pediatric Gastroenterology, Children's Hospital of Nanjing Medical University, 72 Guangzhou Road, \\ Nanjing, China. Email: xinghui7325@sina.com.
}

Background: Liver injury is both very common in infants and children and associated with low immune function. This study aimed to investigate the effect of spleen aminopeptide oral lyophilized powder (SAOLP) on liver injury in infants and children with human cytomegalovirus (HCMV) infection.

Methods: In this prospective observational study, 217 infants and children with both liver damage and HCMV infection who were admitted to the Department of Pediatric Gastroenterology, Children's Hospital of Nanjing Medical University between July 2018 and May 2020 were investigated. The median age of patients was 0.75 years (0.36-3.77 years), with 105 male and 112 female participants. All 217 patients received ursodeoxycholic acid (UDCA) and/or reduced glutathione (GDC) therapy. Of these 217 patients, 114 also received SAOLP. Liver function, cellular immunity levels, HCMV antibody titer, and HCMV-DNA load values were measured 1 day before treatment, and on the second and fourth week after treatment.

Results: After 4 weeks, patients treated with SAOLP showed median levels of serum alanine aminotransferase (ALT), total bilirubin (TB), and direct bilirubin (DB) which were significantly lower than those seen in patients who did not receive it. In addition, the percentage of CD4+ cells was significantly higher in those treated with SAOLP in comparison to those treated with UDCA and/or GDC alone. The number of positive HCMV-immunoglobin M (IgM) patients was also sharply decreased in the group receiving SAOLP.

Conclusions: The addition of SAOLP to UDCA and/or GDC therapy may significantly relieve liver injury and reduce the jaundice index by enhancing immune function and anti-HCMV infection ability in infants and children.

Keywords: Spleen aminopeptide oral lyophilized powder (SAOLP); liver injury; human cytomegalovirus infection (HCMV infection); infants; children

Submitted Jul 03, 2020. Accepted for publication Oct 22, 2020.

doi: $10.21037 / \mathrm{tp}-20-173$

View this article at: http://dx.doi.org/10.21037/tp-20-173

^ ORCID: 0000-0002-6870-9740. 


\section{Introduction}

Liver injury is very common in infants and children. Many causes exist, including viral infection (1-5), drugs $(6,7)$, hereditary metabolic causes $(8,9)$, and autoimmune effects $(10,11)$. As one of the most common causes, the effect of human cytomegalovirus (HCMV) infection is likely related to the underdeveloped immune function seen in this group $(5,12,13)$. Medications currently used to treat liver damage in infants and children include reduced glutathione (GSH) and ursodeoxycholic acid (UDCA). GSH is a tripeptide containing a $\gamma$-amide bond and mercapto group, which is composed of glutamic acid, cysteine, and glycine (14). The active mercapto group combines with free radicals through oxidative dehydrogenation (15). UDCA is a type of nontoxic hydrophilic cholic acid which can enhance the secretory ability of cholestasis hepatocytes by activating mitotic active protein kinase and reducing the concentration of endogenous hydrophobic cholic acid in hepatocytes to achieve the effect of anti-cholestasis $(16,17)$. UDCA can also competitively replace toxic cholic acid molecules on the cell membrane and organelles, and prevent hepatocytes and bile duct cells from being damaged by more toxic cholic acid $(16,17)$.

Liver damage in infants and children is usually associated with low immune function $(18,19)$; however, there is no clinical treatment for liver damage with immunomodulators. Spleen aminopeptide oral lyophilized powder (SAOLP) is an immunomodulator that is composed mainly of peptides and nucleotides extracted from fresh pig spleen (20). It is also used in the treatment of cellular immune dysfunction and autoimmune disorders, such as chronic tonsillitis (21). Spleen aminopeptide enhances viral immunity by inhibiting the secretion of interleukin-4 (IL-4) by Th2 cells and relieving the inhibition of IL-4 on lymphocytes and phagocytosis of macrophages (22). However, there appears to be no clinical evidence demonstrating that SAOLP can ameliorate liver injury in infants and children.

This study thus aimed to evaluate the efficacy and safety of SAOLP in infants and children concurrently receiving UDCA and/or GSH alone for the treatment of liver damage.

We present the following article in accordance with the STROBE reporting checklist (available at http://dx.doi. org/10.21037/tp-20-173).

\section{Methods}

\section{Patients}

A total of $475 \mathrm{HCMV}$-infected infants and children hospitalized in the Department of Pediatric Gastroenterology, Children's Hospital of Nanjing Medical University between July 2018 and May 2020 were initially enrolled into this study. Failure to receive SAOLP according to the protocol resulted in the exclusion of 136 patients. A further 122 patients were excluded as they did not receive liver tests at the prescribed time intervals. The remaining 217 patients included 125 who were $\mathrm{HCMV}$-immunoglobin M (IgM)-positive, 160 with $10^{3}-10^{7}$ copies $/ \mathrm{mL}$ HCMV-DNA load values, and 68 who were positive in both HCMV-IgM and HCMV-DNA load values.

Patients treated with GSH $(n=217)$ and UDCA $(n=113)$ were taken as the study control group. No patient with HCMV infection received standard antiviral treatment. SAOLP was taken as the study object to investigate its efficacy in improving liver function, damage, and reducing the jaundice index and HCMV infection rates. The study was conducted in accordance with the Declaration of Helsinki (as revised in 2013), and was approved by the Ethic Committee of Nanjing Medical University (No. 201806187-1). Informed consent was sought and received from the families of all the patients.

\section{Inclusion and exclusion criteria}

All patients met the inclusion criteria of diagnosed liver damage confirmed by a doubling of serum levels of alanine aminotransferase (ALT) and aspartate aminotransferase (AST) or direct bilirubin (DB), with a concurrent increase in total bilirubin (TB). The diagnosis of HCMV infection was based on the recommendations for diagnosis and prevention and treatment of cytomegalovirus diseases in children (23). In patients with HCMV, the HCMV antibody titer was positive and/or the HCMV-DNA load values were more than or equal to $10^{3}$ copies/mL of the HCMV-DNA load values. All patients tested negative for hepatitis, EpsteinBarr virus, respiratory, and other common viruses, and none were found to have biliary malformation, metabolic liver disease, or drug poisoning hepatitis. Those excluded from the study included HCMV-infected newborns, those with allergy to the medications used, and those with primary immunodeficiency, congenital heart disease, rickets, or malnutrition. Patients who had been previously treated with other immunoenhancers were also excluded.

\section{SAOLP preparation}

Fresh and healthy pig spleens were pretreated then 


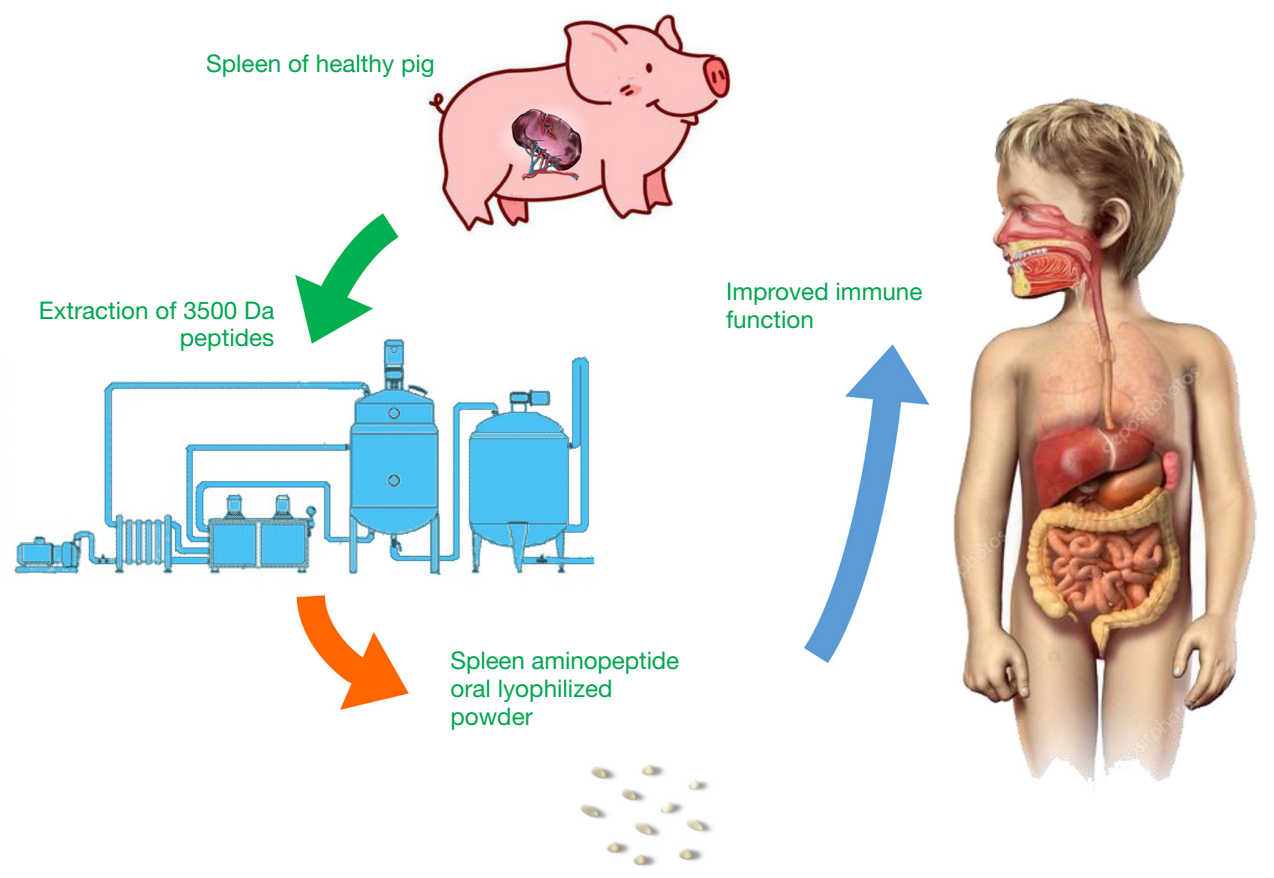

Figure 1 Schematic diagram of spleen aminopeptide oral lyophilized powder preparation.

added into a dehumidified stock solution with precooled temperature below $10{ }^{\circ} \mathrm{C}$ in proportion. Spleen tissue was then treated with a high-speed homogenizer and centrifuged. The supernatant was filtered by a pressure filter after high-speed freezing and centrifugation, and the filter press fluid underwent ultrafiltration. Raw material solution with a molecular weight of less than 10,000 was then prepared. Nanofiltration concentration technology was used for concentration, filling, freeze-drying, and full compression according to specifications. After being sterilized by heat and humidity, the bottles were stored at a temperature below $8{ }^{\circ} \mathrm{C}$ and equipped with cold chain transportation to ensure drug activity. SAOLP was taken on an empty stomach as this increases the contact area between the drug and the gastrointestinal mucosa, promoting absorption (Figure 1).

\section{Regimen protocols}

Patients received UDCA, GSH, and/or SOALP according to the following regimen: GSH $30-60 \mathrm{mg} / \mathrm{kg} / \mathrm{d}$, three times a day, taken orally for 4 weeks; or, GSH added into $5 \%$ glucose solution by intravenous drip, $30-60 \mathrm{mg} / \mathrm{kg} / \mathrm{d}$, once a day, for 2 weeks, then changed to oral administration, $30-60 \mathrm{mg} / \mathrm{kg} / \mathrm{d}$, three times a day, and continued orally for
2 weeks.

UDCA or SAOLP (Zhejiang Feng'an Biopharmaceutical Co., Ltd) $10 \mathrm{mg} / \mathrm{kg} / \mathrm{d}$ was taken orally, twice a day, for 4 weeks. The SAOLP was dissolved into $10 \mathrm{~mL}$ of cold boiled water and administered orally according to the following protocols: $2 \mathrm{mg} / \mathrm{d}$, once a day, taken orally for 4 weeks when the patient was older than 1 year of age; $2 \mathrm{mg} / \mathrm{d}$, once every other day, taken orally for 4 weeks when the age of the patient was less than or equal to 1 year. Before and after treatment, all infants and children were examined for liver function and imaging (Figure 2).

\section{Detection of liver damage and immune function}

Following 2 and 4 weeks of treatment, ALT, AST, TB, indirect bilirubin (IB), and DB levels were measured and compared between the groups. Cellular immune function parameters including $\mathrm{CD}^{+}, \mathrm{CD}^{+}, \mathrm{CD}^{+}, \mathrm{B}$ cells, and natural killer (NK) cells, along with the rate of HCMVDNA load value reduction and antibody HCMV-IgM positive turning negation were also compared.

\section{Statistical analysis}

SPSS 21.0 software was used for statistical analysis. 


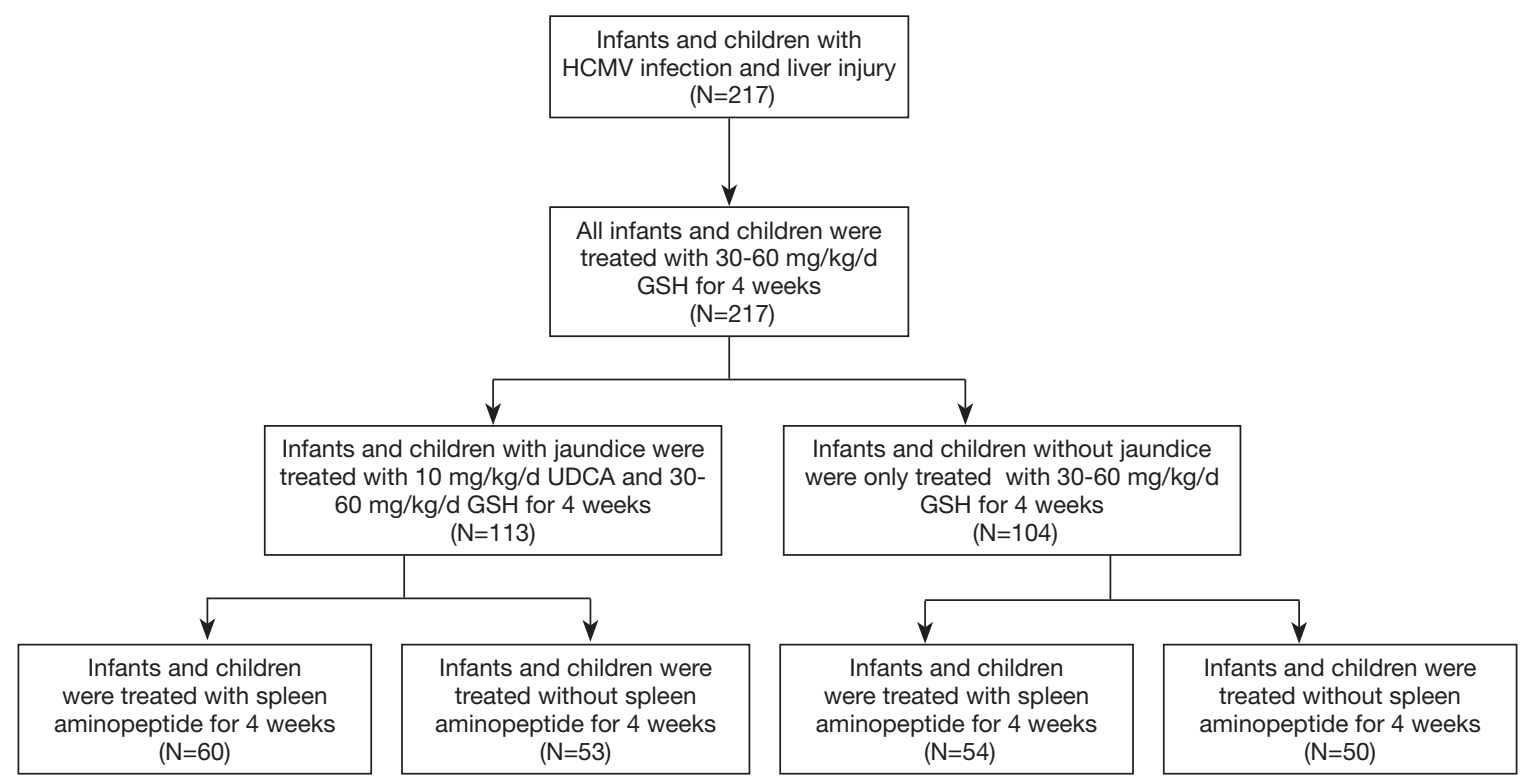

Figure 2 Flow chart of drug therapy for infants and children with liver injury and HCMV infection. HCMV, human cytomegalovirus; GSH, reduced glutathione; UDCA, ursodeoxycholic acid.

Continuous variables are expressed as median [interquartile range (IQR)] and were compared with the Mann-Whitney $\mathrm{U}$ test. Categorical variables are expressed as number (\%) and were compared by $\chi^{2}$ test or Fisher's exact test between patients receiving SAOLP and those not receiving it. Statistical significance was assessed at a $\mathrm{P}$ value $<0.05$.

\section{Results}

\section{Clinical manifestations}

The characteristics of all patients are summarized in Table 1. The patients treated with SAOLP numbered 114 . This group was composed of 55 males and 59 females aged between 1.8 months and 10.9 years and with a median age of 9 months (IQR, 0.36-3.61 years; Table 1). The main clinical manifestations of this group were fever (7\%, 8/114), anorexia $(60.5 \%, 69 / 114)$, weight loss $(18.4 \%, 21 / 114)$, abnormal coagulation $(25.4 \%, 29 / 114)$, liver enlargement (47\%, 55/114), and spleen enlargement (20.1\%, 23/114). In the group of 103 patients who did not receive SAOLP, there were 50 males and 53 females, aged between 1.2 months and 11.4 years, with a median age of 9.1 months (IQR $0.36-$ 4.25 years; Table 1). The main clinical manifestations of this group were fever $(8.7 \%, 9 / 103)$, anorexia $(57.3 \%, 59 / 103)$, weight loss $(15.5 \%, 16 / 103)$, abnormal coagulation $(26.2 \%$, $27 / 103)$, liver enlargement $(46.6 \%, 48 / 103)$, and spleen enlargement $(22.3 \%, 23 / 103)$. There were no statistically significant differences between the two groups with respect to these measures.

\section{Changes of liver function before and after treatment}

Before treatment commenced, the median levels of ALT in those receiving SAOLP and those not receiving it was $189 \mathrm{U} / \mathrm{L}$ (137-251 U/L) and $214 \mathrm{U} / \mathrm{L}$ (155-323 U/L) respectively. After the second week these figures were, 102 U/L (58$146 \mathrm{U} / \mathrm{L}$ ) in the group receiving SAOLP and $125 \mathrm{U} / \mathrm{L}$ (96$175 \mathrm{U} / \mathrm{L})$ in those not receiving it. There was no statistically significant difference in ALT levels between both groups $(\mathrm{P}>0.05)$. The median levels of ALT in patients receiving SAOLP after 4 weeks of treatment, however, was $54 \mathrm{U} / \mathrm{L}$ (37-89 U/L) which was significantly lower than the $72 \mathrm{U} / \mathrm{L}$ (53-123 U/L) in those not receiving it $(\mathrm{P}<0.05$, Table 2).

\section{Changes of jaundice before and after treatment}

Prior to treatment, the median levels of TB and DB were $102.6 \mu \mathrm{mol} / \mathrm{L}(80.2-140.3 \mu \mathrm{mol} / \mathrm{L})$ and $85.9 \mu \mathrm{mol} / \mathrm{L}(65.2-$ $106.8 \mu \mathrm{mol} / \mathrm{L})$ respectively in patients receiving SAOLP and $123.0 \mu \mathrm{mol} / \mathrm{L}(89.6-186.4 \mu \mathrm{mol} / \mathrm{L})$ and $102.6 \mu \mathrm{mol} / \mathrm{L}$ $(68.2-141.0 \mu \mathrm{mol} / \mathrm{L})$ in those not receiving it. There were no significant differences between these groups $(\mathrm{P}>0.05)$. 
Table 1 Demographics and baseline characteristics of patients with liver damage

\begin{tabular}{|c|c|c|c|c|}
\hline Characteristics & Total & \multicolumn{2}{|c|}{ Spleen aminopeptide } & $P$ value \\
\hline Patients (n) & 217 & 103 & 114 & - \\
\hline \multicolumn{5}{|l|}{ Age, n (\%) } \\
\hline$<1$ & $129(59.4)$ & $63(61.2)$ & $66(57.9)$ & 0.824 \\
\hline$\geq 6$ & $62(28.6)$ & $29(28.2)$ & $33(28.9)$ & \\
\hline Age (year) & $0.75(0.36-3.77)$ & $0.76(0.36-4.25)$ & $0.75(0.36-3.61)$ & 0.890 \\
\hline \multicolumn{5}{|l|}{ Gender, n (\%) } \\
\hline Male & $105(48.4)$ & $50(48.5)$ & $55(48.2)$ & 0.965 \\
\hline Yes & $113(52.1)$ & $53(51.5)$ & $60(52.6)$ & 0.863 \\
\hline No & $104(47.9)$ & $50(48.5)$ & $54(47.4)$ & \\
\hline Fever, n (\%) & $17(7.8)$ & $9(8.7)$ & $8(7.0)$ & 0.638 \\
\hline Anorexia, n (\%) & $128(59)$ & $59(57.3)$ & $69(60.5)$ & 0.627 \\
\hline Weight loss, n (\%) & $37(17.1)$ & $16(15.5)$ & $21(18.4)$ & 0.572 \\
\hline Coagulation dysfunction, n (\%) & $56(25.8)$ & $27(26.2)$ & $29(25.4)$ & 0.896 \\
\hline Liver enlargement, n (\%) & $103(47.5)$ & $48(46.6)$ & $55(47.0)$ & 0.809 \\
\hline Spleen enlargement, n (\%) & $46(21.2)$ & $23(22.3)$ & $23(20.1)$ & 0.698 \\
\hline
\end{tabular}

$\mathrm{P}$ values comparing with spleen aminopeptide and without spleen aminopeptide are from $\chi^{2}$ test, Fisher's exact test, or Mann-Whitney $U$ test.

After the second week, however, the median level of DB was $40.8 \mu \mathrm{mol} / \mathrm{L}(26.2-65.4 \mu \mathrm{mol} / \mathrm{L})$ in those receiving SAOLP, which was significantly lower than the $53.2 \mu \mathrm{mol} / \mathrm{L}(34.2-$ $70.4 \mu \mathrm{mol} / \mathrm{L})$ observed in those not receiving it $(\mathrm{P}<0.05)$. Median levels of TB and $\mathrm{DB}$ were also significantly lower in the SAOLP treatment group at 4 weeks $[32.5 \mu \mathrm{mol} / \mathrm{L}$ $(23.5-45.5 \mu \mathrm{mol} / \mathrm{L})$ and $19.2 \mu \mathrm{mol} / \mathrm{L}(12.8-35.7 \mu \mathrm{mol} / \mathrm{L})]$, in comparison to the group not receiving it $[46.1 \mu \mathrm{mol} / \mathrm{L}$ $(26.4-68.7 \mu \mathrm{mol} / \mathrm{L})$ and $35.7 \mu \mathrm{mol} / \mathrm{L}(20.8-45.9 \mu \mathrm{mol} / \mathrm{L})]$ $(\mathrm{P}<0.05$, Table 2).

\section{Changes of immune function before and after treatment}

Before treatment commenced, the percentage of $\mathrm{CD} 4^{+}$ cells in patients receiving SAOLP was $39.2 \% \pm 6.9 \%$, and $40.6 \% \pm 5.8 \%$ in those not receiving it. There was no significant difference between the groups $(\mathrm{P}>0.05)$. After 4 weeks, however, the percentage of $\mathrm{CD}^{+}$cells in the group receiving SAOLP was significantly higher $(46.2 \pm 7.8)$ in comparison to the group not receiving it $(42.3 \% \pm 5.8 \%)$ $(\mathrm{P}<0.05$, Table 3).

\section{Changes of HCMV infection rates before and after treatment}

While all 217 patients were seen to have had cytomegalovirus infection prior to treatment, 125 were IgM-positive, and 160 showed more than or equal to $10^{3}$ copies/mL of the HCMV-DNA load values. Both HCMV$\operatorname{IgM}$ positive and HCMV-DNA were found in 68 cases. In patients receiving SAOLP, 63 (50.4\%) had positive HCMV-IgM, 66 (76.7\%) showed $10^{3}-10^{4}$ copies/mL of HCMV-DNA load values in the peripheral blood, 11 (12.8\%) showed $10^{5}-10^{6}$ copies $/ \mathrm{mL}$, and 1 (1.2\%) showed $10^{7}$ copies/mL. In patients not treated with SAOLP, 62 (49.6\%) had positive HCMV-IgM, 72 (84.7\%) showed 
Table 2 Efficacy of spleen aminopeptide on liver damage

\begin{tabular}{|c|c|c|c|c|}
\hline Variables & Total & \multicolumn{2}{|c|}{ Spleen aminopeptide } & $P$ value \\
\hline \multicolumn{5}{|c|}{ Liver transaminase level ( $1 \mathrm{~d}$ before treatment) } \\
\hline ALT (U/L) & $201[142-271]$ & $189[137-251]$ & 214 [155-323] & 0.478 \\
\hline AST (U/L) & 139 [97-215] & 123 [89-201] & $155[102-258]$ & 0.067 \\
\hline $\mathrm{ALT}(\mathrm{U} / \mathrm{L})$ & $123[80-161]$ & $125[96-175]$ & $102[58-146]$ & 0.001 \\
\hline AST (U/L) & $91[56-112]$ & $96[64-110]$ & $76[43-114]$ & 0.151 \\
\hline \multicolumn{5}{|c|}{ Liver transaminase level ( $4 \mathrm{w}$ after treatment) } \\
\hline ALT (U/L) & 65 [42.3-103] & $72[53-123]$ & 54 [37-89] & 0.003 \\
\hline TB $(\mu \mathrm{mol} / \mathrm{L})$ & $103.4(87.6-152.8)$ & $123.0(89.6-186.4)$ & $102.6(80.2-140.3)$ & 0.137 \\
\hline $\mathrm{DB}(\mu \mathrm{mol} / \mathrm{L})$ & $96.5(65.4-122.2)$ & $102.6(68.2-141.0)$ & $85.9(65.2-106.8)$ & 0.103 \\
\hline \multicolumn{5}{|c|}{ Jaundice index ( $2 \mathrm{w}$ after treatment) } \\
\hline TB $(\mu \mathrm{mol} / \mathrm{L})$ & $67.2(44.8-91.7)$ & $70.9(46.4-102.2)$ & $60.15(43.5-78.5)$ & 0.070 \\
\hline $\mathrm{DB}(\mu \mathrm{mol} / \mathrm{L})$ & $48.2(31.6-67.5)$ & $53.2(34.2-70.4)$ & $40.8(26.2-65.4)$ & 0.046 \\
\hline \multicolumn{5}{|c|}{ Jaundice index ( $4 \mathrm{w}$ after treatment) } \\
\hline TB $(\mu \mathrm{mol} / \mathrm{L})$ & $35.7(23.8-57.2)$ & $46.1(26.4-68.7)$ & $32.5(23.5-45.5)$ & 0.007 \\
\hline $\mathrm{DB}(\mu \mathrm{mol} / \mathrm{L})$ & $28.5(18.0-39.7)$ & $35.7(20.8-45.9)$ & $19.2(12.8-35.7)$ & 0.002 \\
\hline
\end{tabular}

Data are median (IQR). P values comparing with spleen aminopeptide and without spleen aminopeptide are from $\chi^{2}$, Fisher's exact test, or Mann-Whitney U test.

$10^{3}-10^{4}$ copies/mL of HCMV-DNA load values in the peripheral blood, $9(10.6 \%)$ showed $10^{5}-10^{6}$ copies $/ \mathrm{mL}$, and $1(1.2 \%)$ showed $10^{7}$ copies $/ \mathrm{mL}$. There were no significant differences between both groups with respect to positive HCMV-IgM rates and HCMV-DNA load values (Table 4).

After 4 weeks of treatment with SAOLP, the percentage of positive HCMV-IgM patients was sharply decreased compared with those not receiving it $[86(39.6 \%) v s$. $125(57.6 \%), \mathrm{P}<0.05]$. A total of $38(33.3 \%)$ of patients treated with SOALP had positive HCMV-IgM, which was significantly lower than those not treated with it [48 (47.1\%), $\mathrm{P}<0.05]$.

Of the patients treated with SAOLP, 44 (55.7\%) showed $10^{3}-10^{4}$ copies/mL of HCMV-DNA load values in the peripheral blood, $3(3.8 \%)$ showed $10^{5}-10^{6}$ copies $/ \mathrm{mL}$, and none showed $10^{7}$ copies $/ \mathrm{mL}$. In those not treated with SAOLP, 48 (47.1\%) had positive HCMV-IgM, 33 (46.5\%) showed $10^{3}-10^{4}$ copies/mL of HCMV-DNA load values in the peripheral blood, $1(1.4 \%)$ showed $10^{5}-10^{6}$ copies $/ \mathrm{mL}$, and none showed $10^{7}$ copies $/ \mathrm{mL}$. There were no significant differences between both groups in the HCMV-DNA load values (Table 4).

\section{Comparison of adverse reactions between both groups}

Adverse reactions occurred in 14 patients (12.3\%) receiving SAOLP. Allergic rash was seen in 9 patients, nausea in 3 , and headache in 2. In the group not receiving SAOLP, 12 patients $(11.7 \%)$ exhibited adverse reactions. Allergic rash was seen in 7 patients, nausea in 2, and liver damage in 3. There were no significant differences between the groups $(\mathrm{P}>0.05)$.

\section{Discussion}

Both GSH and UDCA are often used in the treatment of 
Table 3 Effects of spleen aminopeptide on cellular immune function

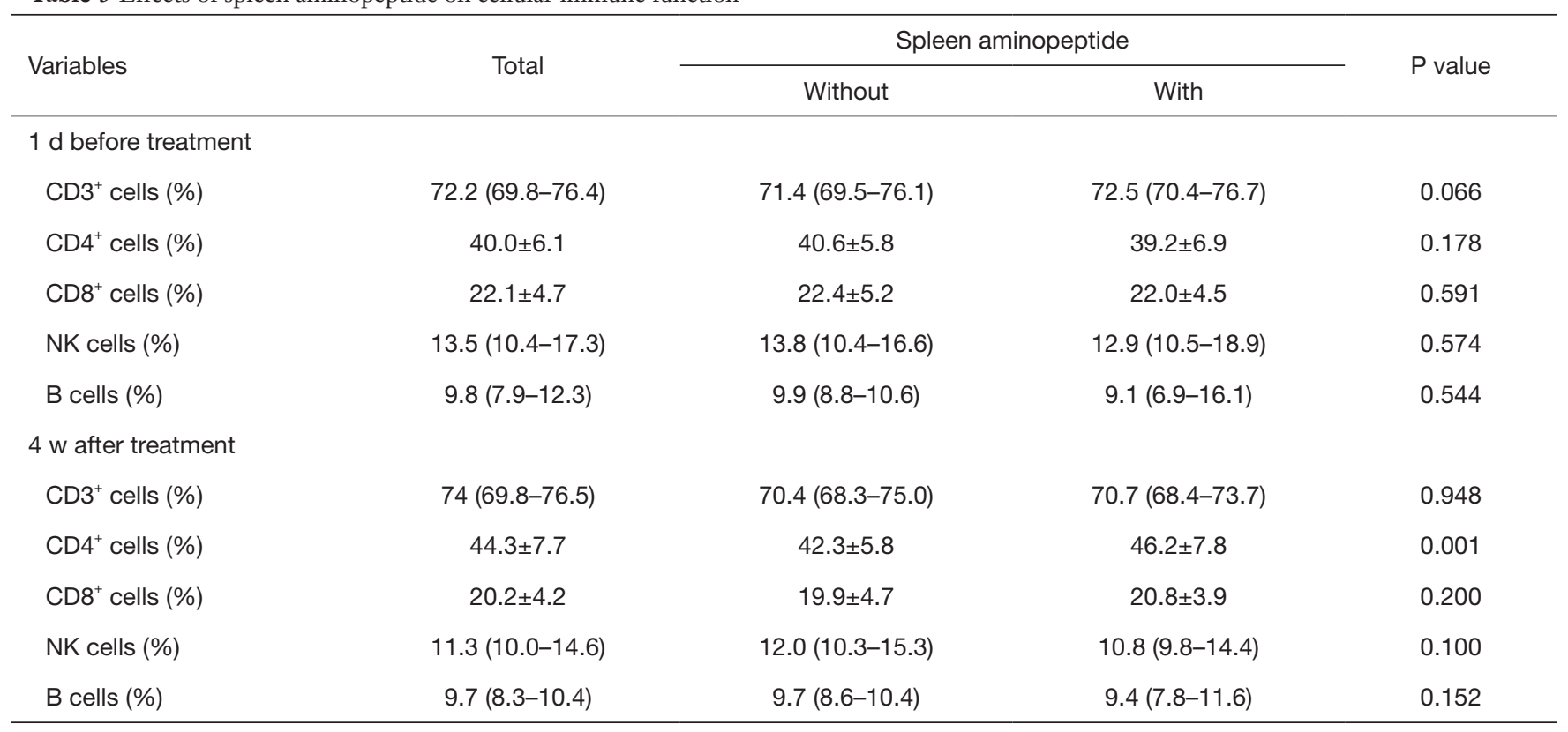

Data are median $(I Q R)$ or mean \pm SD. P values comparing with spleen aminopeptide and without spleen aminopeptide are from $\chi^{2}$, Fisher's exact test, or Mann-Whitney $U$ test.

Table 4 Effects of spleen aminopeptide on cytomegalovirus infection

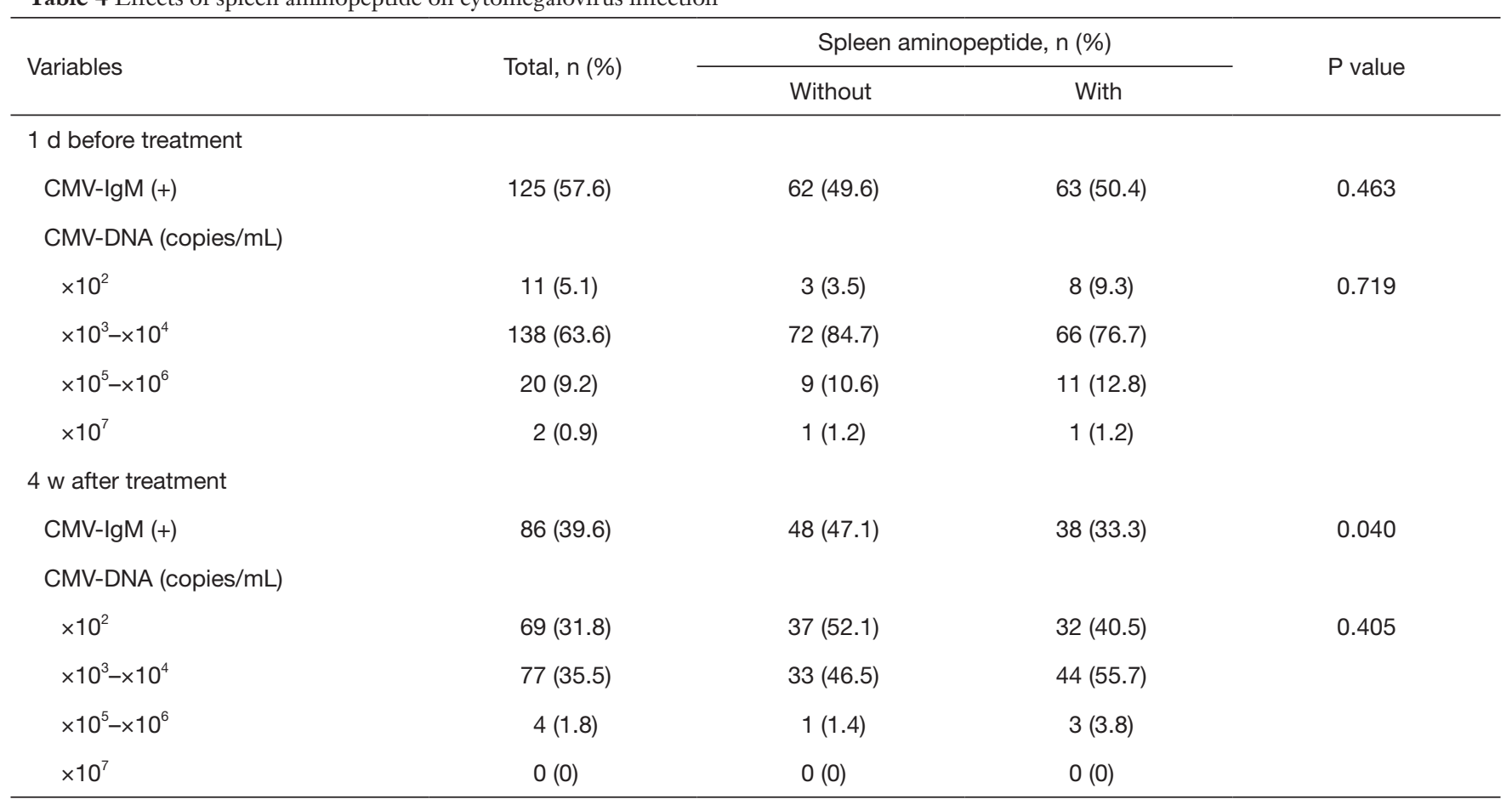

Data are $\mathrm{n}(\%)$. $\mathrm{P}$ values comparing with spleen aminopeptide and without spleen aminopeptide are from $\chi^{2}$, Fisher's exact test. 
liver damage in infants and children. While GSH functions through oxidative dehydrogenation and detoxification, UDCA resists cholestasis and replaces toxic cholic acid molecules. In this study, UDCA and/or GSH alone were used to treat liver injury with or without jaundice. The level of ALT after the fourth week of treatment was significantly lower than that seen before treatment. Levels of TB and $\mathrm{DB}$ in the second and fourth weeks after treatment were significantly lower than those seen before treatment, suggesting that UDCA and/or GSH alone can effectively reduce liver damage and promote jaundice clearance in infants and children. When SAOLP was added to this regimen, levels of ALT after 4 weeks were significantly lower than those seen with UDCA and/or GSH treatment alone. Levels of serum DB at the second week and both $\mathrm{TB}$ and $\mathrm{DB}$ at the fourth week were also sharply lower in those treated with SAOLP. This suggests that the addition of SAOLP to UDCA and/or GDC alone can effectively improve jaundice clearance rates, promote bile excretion, enhance liver protective effects, and reduce liver damage.

Improvements in immune function and antiviral capability have been observed with the use of SAOLP (24). Studies have pointed out that spleen aminopeptide can improve the function of helper $\mathrm{T}$ cells, promote the secretion of IL-2 and interferon gamma (INF- $\gamma$ ) by Th1 cells, induce lymphocyte transformation in vivo, and activate the activity of the mononuclear megaphagocyte system (22). In this study, the percentage of $\mathrm{CD}^{+}$cells in infants and children treated with SAOLP after 4 weeks was significantly higher than that seen in those not receiving it. This suggests the improvement of liver injury and clearance of jaundice might be related to the enhancement of cellular immune function accompanied by an increase in $\mathrm{CD} 4^{+}$cells.

Spleen aminopeptide also plays a synergistic role in the treatment of HCMV infection. The therapeutic effect of spleen aminopeptide combined with ganciclovir in the treatment of HCMV infection in children is better than that of ganciclovir alone, suggesting an improvement in immune function and enhancement of antiviral ability (24). Although there was no significant difference in the HCMV-DNA load values in the blood between the SAOLP treatment and non-treatment groups, the positive rate of HCMV-IgM titer in those treated with SAOLP was significantly lower than those treated with UDCA and/or GSH alone. This indicates SAOLP may enhance the ability of anti-HCMV infection as a result of immune function enhancement.

There are several imitations to this study. Firstly, this was a single center study and the diversity and quantity of enrolled patients were limited. Secondly, not all patients with liver injury in outpatient or inpatient settings were admitted to the study. Finally, a large number of patients, 258 in total, were excluded because of poor compliance.

Our results suggest that SAOLP can significantly reduce liver damage and promote jaundice clearance in infants and children with liver damage. In addition, SAOLP may increase the percentage of $\mathrm{CD}^{+}$cells and the decrease of the positive rate of HCMV-IgM titer. Further studies using multicenter, large sample clinical trials are needed.

\section{Acknowledgments}

Funding: The Project was Support by the Nanjing Science and Technology Development Project (No. 201605045).

\section{Footnote}

Reporting Checklist: The authors have completed the STROBE reporting checklist. Available at http://dx.doi. org/10.21037/tp-20-173

Data Sharing Statement: Available at http://dx.doi. org/10.21037/tp-20-173

Peer Review File: Available at http://dx.doi.org/10.21037/tp20-173

Conflicts of Interest: All authors have completed the ICMJE uniform disclosure form (available at http://dx.doi. org/10.21037/tp-20-173). The authors have no conflicts of interest to declare.

Ethical Statement: The authors are accountable for all aspects of the work in ensuring that questions related to the accuracy or integrity of any part of the work are appropriately investigated and resolved. The study was conducted in accordance with the Declaration of Helsinki (as revised in 2013), and was approved by the Ethic Committee of Nanjing Medical University (No. 201806187-1) and informed consent was taken from all the patients.

Open Access Statement: This is an Open Access article distributed in accordance with the Creative Commons Attribution-NonCommercial-NoDerivs 4.0 International License (CC BY-NC-ND 4.0), which permits the noncommercial replication and distribution of the article with the strict proviso that no changes or edits are made and the 
original work is properly cited (including links to both the formal publication through the relevant DOI and the license). See: https://creativecommons.org/licenses/by-nc-nd/4.0/.

\section{References}

1. Xu L, Liu J, Lu M, et al. Liver injury during highly pathogenic human coronavirus infections. Liver Int 2020;40:998-1004.

2. Crouchet E, Baumert TF, Schuster C. Hepatitis C virusapolipoprotein interactions: molecular mechanisms and clinical impact. Expert Rev Proteomics 2017;14:593-606.

3. Sozzi V, Shen F, Chen J, et al. In vitro studies identify a low replication phenotype for hepatitis $B$ virus genotype $\mathrm{H}$ generally associated with occult HBV and less severe liver disease. Virology 2018;519:190-6.

4. Prost S, Crossan CL, Dalton HR, et al. Detection of viral hepatitis $\mathrm{E}$ in clinical liver biopsies. Histopathology 2017;71:580-90.

5. Li WW, Shan JJ, Lin LL, et al. Disturbance in plasma metabolic profile in different types of human cytomegalovirus-induced liver injury in infants. Sci Rep 2017;7:15696.

6. Kleiner DE. Recent Advances in the histopathology of drug-induced liver injury. Surg Pathol Clin 2018;11:297-311.

7. Björnsson ES. Drug-induced liver injury due to antibiotics. Scand J Gastroenterol 2017;52:617-23.

8. Reichert MC, Lammert F. ABCB4 Gene Aberrations in Human Liver Disease: An Evolving Spectrum. Semin Liver Dis 2018;38:299-307.

9. Hirayama S, Nagasaka H, Honda A, et al. Cholesterol Metabolism Is Enhanced in the Liver and Brain of Children With Citrin Deficiency. J Clin Endocrinol Metab 2018;103:2488-97.

10. Gehrke N, Hövelmeyer N, Waisman A, et al. Hepatocytespecific deletion of IL1-RI attenuates liver injury by blocking IL-1 driven autoinflammation. J Hepatol 2018;68:986-95.

11. Tabet E, Gelu-Simeon M, Genet V, et al. Chlordecone potentiates auto-immune hepatitis and promotes brain entry of MHV3 during viral hepatitis in mouse models. Toxicol Lett 2018;299:129-36.

12. Goel A, Chaudhari S, Sutar J, et al. Detection of cytomegalovirus in liver tissue by polymerase chain reaction in infants with neonatal cholestasis. Pediatr Infect Dis J 2018;37:632-6.

13. Hu J, Zhao H, Lou D, et al. Human cytomegalovirus and Epstein-Barr virus infections, risk factors, and their influence on the liver function of patients with acute-onchronic liver failure. BMC Infect Dis 2018;18:577.

14. Glutathione, reduced (GSH). Monograph. Altern Med Rev 2001;6:601-7.

15. Lv H, Zhen C, Liu J, et al. Unraveling the potential role of glutathione in multiple forms of cell death in cancer therapy. Oxid Med Cell Longev 2019;2019:3150145.

16. Guarino MP, Cocca S, Altomare A, et al. Ursodeoxycholic acid therapy in gallbladder disease, a story not yet completed. World J Gastroenterol 2013;19:5029-34.

17. Paumgartner G, Beuers U. Ursodeoxycholic acid in cholestatic liver disease: mechanisms of action and therapeutic use revisited. Hepatology 2002;36:525-31.

18. Corazza N, Badmann A, Lauer C. Immune cellmediated liver injury. Semin Immunopathol 2009;31:267-77.

19. Tiegs G.Cellular and cytokine-mediated mechanisms of inflammation and its modulation in immune-mediated liver injury. Z Gastroenterol 2007;45:63-70.

20. Ai L, Liu J, Jiang Y, et al. Specific PCR method for detection of species origin in biochemical drugs via primers for the ATPase 8 gene by electrophoresis. Mikrochim Acta 2019;186:634.

21. Shen XF, Zhou A, Huang Q. An Analysis of spleen aminopeptide oral lyophilized powder in the treatment of children after tonsillectomy. Lin Chuang Er Bi Yan Hou Tou Jing Wai Ke Za Zhi 2017;31:1690-2.

22. Qing PP, Liu Rq, LV D. Curative effect of spleen aminopeptide oral lyophilized powder combined with recombinant human interferon $-2 \mathrm{~b}$ ointment on verruca plana and its influence on T-lymphocyte subsets, IL-2, IL4, INF- in adolescent patients. Pi Fu Xing Bing Xue Za Zhi 2016;38:1-4.

23. Subspecialty Group of Infectious Diseases, The Society of Pediatrics, Chinese Medical Association, National Pediatric Clinical Virology Cooperative Group. A proposal for the diagnosis, treatment and prophylaxis of cytomegalovirus diseases in children. Zhonghua Er Ke Za 
Zhi 2012;50:290-2.

24. Luo XF, Xiao H, Cai J. The effect of spleen aminopeptide combined with ganciclovir in the treatment of children cytomegalovirus infection. Zhong Guo Lin Chuang He Li

Cite this article as: Wu Y, Dong $\mathrm{X}, \mathrm{Wu} \mathrm{R}$, Zheng $\mathrm{X}$, Jin $\mathrm{Y}$, Yang H. Efficacy and safety of spleen aminopeptide oral lyophilized powder in ameliorating liver injury in infants and children with human cytomegalovirus infection: a single-center study in China. Transl Pediatr 2021;10(1):136-145. doi: 10.21037/ tp-20-173
Yong Yao Za Zhi 2016;9:36-7.

(English Language Editors: B. Draper and J. Gray) 